\title{
Telemedicine - the eye of 2020's perfect storm
}

\author{
Marcel-Alexandru Găină, Roxana Chiriță
}

\begin{abstract}
Marcel-Alexandru Găină- M.D., Ph.D. student, "Grigore T. Popa" University of Medicine and
\end{abstract} Pharmacy, Junior Psychiatrist, "Socola Institute of Psychiatry", Iași, Romania;

Roxana Chiriță- M.D., Ph.D. Professor, Department of Psychiatry "Grigore T. Popa" University of Medicine and Pharmacy, Senior Psychiatrist, "Socola Institute of Psychiatry", Iași, Romania.

Ever since the start of the SARS-COV2 pandemic, the lack of a preexisting legislative framework pertaining to telehealth services has become quite an elephant in the room. In this regard, on March 21, 2020 the Romanian Association of Psychiatry and Psychotherapy (ARPP), as the representative forum of the psychiatrists, submitted a public request to the National Health Insurance House, the Ministry of Health and the Romanian Physicians' College, asking for such a legislative regulation regarding telemedicine services, and also providing examples from the United Kingdom and the United States of America.

November 18, 2020 introduces a legislative framework for telemedicine in Romania, by Emergency Ordinance 196 amending and supplementing Law no. 95/2006 regarding the healthcare reform.

The main reason behind this decision is to reduce to a minimum the risk of contracting various pathogens, additionally to extend the provision of medical services to secluded rural areas, and to increase the effectiveness of the medical act as well as its efficiency in terms of its economic yield. However, the law also mentions that the rushing of this legislative regulation is not merely connected to the current pandemic context, nor does it emerge solely at the request of the ARPP; but the failure to adopt such measures would lead to the impossibility of meeting the deadline for the objectives set as per Section 2 ("Healthcare Services 2014-2020") of the National Health Strategy Plan, which would have a major impact on the state budget. It is an ample exercise of imagination to conceive that such a project could have been set up as of 2014, from the perspective of the impact that the SARS-COV-2 pandemic would have on patients' accessibility to healthcare services - which is currently considerably endangered already. 
The year 2020 has placed even the most advanced health systems worldwide under a fair amount of additional pressure. At the media level, an aggressive promotion of the pandemic has been overshadowing regular pathology, to which a medical system paralyzed by the massive influx of severe SARS-COV2 is now allocating fewer and fewer resources.

If the impact of the pandemic on the Romanian health system is not as significant at the institutional level as in countries where private insurance systems require copayment as indispensable for survival, perhaps this is the right time to create a much-needed infrastructure and to offer professionals adequate training courses while also generating public awareness, so that both doctors and patients may acknowledge the availability of the telemedical approach, both now and after the pandemic.

The concept of telehealth includes not only telemedicine, but also the way of promoting medical education through indirect means. Legislatively, teleconsultation (art. 30, 2nd paragraph) is specified as representing the sum of the interventions done by the doctor in the interest of the patient, in order to prevent, diagnose and treat diseases. Teleexpertise (art. 30, 3rd paragraph), is the legal meeting framework for doctors regarding case management, and does not require the presence of the patient. Telecare (art. 30, 4th paragraph) consists of direct assistance through an interventional process done by a a doctor towards another practitioner who aids for a patient who is remote. Teleradiology (art. 30, 5th paragraph) brings into Romania the background radiological practice of European states, allowing the interpretation of imaging results disseminated remotely in electronic formats, and telepathology (art. 30 , 6th paragraph) confirms the possibility of collaboration between pathologists/histologists with reference to microscopic images. Telemonitoring (art. 30,7 th paragraph) is a breath of fresh air as it offers the possibility to manage the therapeutic conduct and health of the patient by interpreting the data obtained by the patient or other medical staff with a standard approved equipment (1). This aspects are already successfully applied in renowned hospitals worldwide, where systems linked in series of electronic tablets allow the patient (even the hospitalized) to obtain firm feedback on his request, thus saving time and personal protective equipment) (2).

The main advantages of telemedicine are: the extensive coverage of the rural environment (this being one of the criteria for approving the settlement of services in the American health insurance system), reduced waiting time and time spent travelling to a doctor's office, reduced risk of contamination and, last but not least, a decreased amount of protective materials used (3).

In Romania, the relatively late introduction of the internet infrastructure has determined the use of a superior technology and, therefore, a greater coverage and quality of internet services, as the country is currently ranked 3rd worldwide for fixed broadband acording to SpeedTest.net review of October 2020 (Download 188.55Mbps; Upload 128.74Mbps; Latency $12 \mathrm{~m} / \mathrm{s}$ ).

The technological conditions are favorable, especially given that, with the recent adoption of online educational courses, many of the isolated villages have come in contact with online platforms and video 
conferencing devices for the first time. However, in order not to deepen inequalities regarding the access of vulnerable people to health services, there is a need to implement a government strategy that ensures the minimum necessary for online consultations.

2020 brings an exponential increase in the stock market value of all internet technology platforms dedicated to videoconferencing, and especially those dedicated exclusively to telemedicine, this being noteworthy as these platforms invest a large part of their resources in security, thus meeting one of the mandatory criteria specified in the law.

Mental health has a great contribution to the quality of life, as a person with resilient biopsycho-social resources can tolerate with dignity even an unfortunate diagnosis. Perhaps no other medical specialty is better suited to telemedicine services than Psychiatry, given that the first form of video telemedicine, which took place 70 years ago in the United States, was a psychiatric consultation. Up to that point, only radio interventions had been recorded in the case of medical events on seagoing ships.

Outpatient telepsychiatric services can provide access to medication for people with various emotional or anxiety disorders and can ease the can ease the pressure and can prevent overcrowding in the emergency rooms and on psychiatric hospitals of the emergency rooms and of psychiatric hospitals (4).

Psychotherapy in 2020 is the necessary, but also the forbidden fruit - as it is often inaccessible to the general population. This period has determined both an exponential increase in the anxiety and depression inside covid wards, but also of pre-existing anxiety disorders in terms of intensity/duration, and the emergence of new cases in the general population, too.

Currently, collective trauma activates the ancestral mechanisms of survival. According to psychotraumatological theories, the resonance at the level of collective mental health will be more strongly felt once the pandemic is overcome, as then the collective trauma will perlaborate at an individual level. Therefore, it is of the utmost importance that at least the post-pandemic scenario finds the specialists ready to adopt telepsychiatry as a technique (5).

Exposure therapy is a true gold standard for specific anxiety disorders.Technological leaps facilitate access to virtual reality. Preinstalling a software and sending the virtual headset via courier services to the patient can provide assisted therapeutic exposure through telemedicine services even in current pandemic conditions.

Thus, after an intitial session that may or may not take place with the patient present in person initial session, the individualized manner of exposure can determine the completion of the therapeutic process in the comfort of the individual's home, without the risk of exposure.

For now, there is still no clear legislative regulation of telepsychotherapy services, but there is a possibility that they may be included in medical services; this aspect requires the confirmation of the Romanian College of Psychologists.

From the psychotherapeutic perspective, from the over 400 recognised schools worldwide, we can say that in their training, 
.

psychotherapists will choose the techniques they resonate with. Cognitive behavioral therapy, the only one scientifically validated from the perspective of efficacy and comparable to medication, easily finds its applicability in telepsychotherapy areas.

Contemporary medicine training knows a direction towards specificity. Medico universalis is no longer in high demand, because only ultra-specialization leads to an effective medical act. It is not uncommon to have surgeons who treat only a certain affliction, sometimes through a single specific approach, but for which they have the highest percentage of success. Psychiatry goes in the same direction, and it is precisely the need to address problems related to mental disorders from a threedimensional, bio-psycho-social perspective, that brings into our attention the increasingly well-defined branching of palliative care, addiction, and anxiety and emotional disorders - which can well integrate psychotherapeutic treatment options.

It is worth mentioning that, with the availability of $5 \mathrm{G}$ networks, telesurgery has become possible, the latency of transmitting the transcontinental signal being finally below the limit of 100 milliseconds. Technological advancements such as the DaVinci or ZEUS robotic systems, linked using fiber optics, and the above-mentioned $5 \mathrm{G}$ connection can offer the possibility to perform transatlantic surgery, in real time. Telemedicine will experience an extension of the services and maneuvers used with the introduction of haptic sensors through which patient palpation and percussion will be possible remotely - listening and disseminating the recording is already possible through pre-existing stethoscopes using bluetooth technology. Thus, it becomes a matter of personal choice whether or not you turn to a surgeon with a success rate that is statistically higher by $30 \%$, depending on your affliction, even though he may be located over $5000 \mathrm{~km}$ away.

Health policies will always pay off over a variable period of time. For now, we must aim for health policies adapted to the characteristics of our health system. Thus, the DRG system was adopted for the simple fact that it simplifies the accounting process of the verification, although a national health insurance system is not suitable for it. The main consequences remain: the distorted reporting and the need to justify funding, in the absence of a centralized selfregulatory mechanism.

The health card is a hindrance in the development of telemedicine services, thus requiring law specification that circumvents its mandatory use, in order to process and validate the consultation. A possible validation within 15-30 days at the general practitioner's office could facilitate the accessibility to these services.

The instability of the currently implemented IT system, as well as the lack of a centralized interdisciplinary IT system raise questions regarding the long-term viability of the current system, and digitalization is a premise that involves a Prometheic effort for an ageing state apparatus. Is a bureaucratic deadlock needed for the medical staff to request its reform?

Within 45 days from the emergency ordinance confirming the validity of telemedicine, we will have a definite regulation of specialties and services, conditions of organization and operation, management and quality standards but 
Bulletin of Integrative Psychiatry O New Series ODecember 2020 ○ Year XXVI ONo. 4 (87)/17 (1) especially the means of providing telemedicine services. It is our duty to speak our minds now, or choose to remain silent.

\section{REFERENCES}

1. Ordonanța de urgenţă nr. 196 din 18 noiembrie 2020 pentru modificarea şi completarea Legii nr. 95/2006 privind reforma în domeniul sănătății, Guvernul României, publicat în Monitorul Oficial nr. 1108 din 19 noiembrie 2020;

2. Mann DM, Chen J, Chunara R et al. COVID-19 transforms health care through telemedicine: evidence from the field. Journal of the American Medical Informatics Association 2020; 27(7): 1132 - 1135;

3. Isabelle Reinhardt, Gouzoulis-Mayfrank E, Zielasek J. Use of Telepsychiatry in Emergency and Crisis Intervention: Current Evidence. Current Psychiatry Reports 2019; 21(8): 63;

4. Boldrini T, Lomoriello AS, Del Corno F et al. Psychotherapy During COVID-19: How the Clinical Practice of Italian Psychotherapists Changed During the Pandemic. Frontiers in Psychology 2020; 11: 591170;

5. Perera SR, Gambheera H, Williams SS. "Telepsychiatry" in the time of COVID-19: Overcoming the challenges. Indian Journal of Psychiatry 2020; 62(9): 391 - 394. 